\title{
Active Damping Method Using Grid-Side Current Feedback for Active Power Filters with LCL Filters
}

\author{
Shiying Tang ${ }^{\dagger}$, Li Peng*, and Yong Kang* \\ $\dagger^{*}$ Dept. of Electrical and Electronics Eng., Huazhong University of Science and Technology, Wuhan, China
}

\begin{abstract}
LCL filters installed at converter outputs offer a higher harmonic attenuation than L filters. However, as a three order resonant circuit, it is difficult to stabilize and has a risk of oscillating with the power grid. Therefore, careful design is required to damp LCL resonance. Compared to a passive damping method, an active damping method is a more attractive solution for this problem, since it avoids extra power losses. In this paper, the damping capabilities of capacitor current, capacitor voltage, and grid-side current feedback methods, are analyzed under the discrete-time state-space model. Theoretical analysis shows that the grid-side current feedback method is more suitable for use in active power filters, because it can damp LCL resonance more effectively than the other two methods when the ratio of the resonance and the control frequency is between 0.225 and 0.325 . Furthermore, since there is no need for extra sensors for additional states measurements, this method provides a cost-efficient solution. To support the theoretical analysis, the proposed method is tested on a 7-kVA single-phase shunt active power filter.
\end{abstract}

Key Words: Active damping, Current control, Generalized integrator, LCL filter, Shunt active power filter

\section{INTRODUCTION}

In many grid-connected applications such as active rectifiers, distributed generating systems, and shunt active power filters (APFs), voltage source converters (VSCs) are commonly connected to the power grid through a simple L filter. In order to sufficiently attenuate the switching harmonics caused by VSCs, high values of inductances are usually needed. It makes the whole system bulky and less cost-efficient. It also causes a poor dynamic response, especially in high power applications. LCL filters seem to be a good solution for this problem, since they offer a higher harmonic attenuation even with smaller inductances when compared to simple L filters [1]-[5].

However, as a three order resonant circuit, LCL filters are difficult to stabilize and have a risk of oscillating with the power grid, due to the zero impedance at the resonant frequency. Therefore, careful design is required to damp LCL resonance. A passive damping method [6], using resistors in series with filter capacitors, provides a simple way to damp LCL resonance, but extra power is depleted by these damping resistors, which reduces the system efficiency and the attenuation of switching harmonics. Therefore, many active damping methods, which attempt to damp the resonance by control, have been proposed in the literature.

The most commonly used states for active damping are capacitor voltage and current. In [7], the LCL resonance was damped by a lead-lag feedback of the capacitor voltage

\footnotetext{
Manuscript received Dec. 8, 2010; revised Feb. 16, 2011

Recommended for publication by Associate Editor Jun-Keun Ji.

$\dagger$ Corresponding Author: sy.tang@qq.com

Tel: +86-027-87543071, Fax: +86-027-87543658, HUST

* Dept. of Electrical and Electronics Eng., HUST, China
}

to the voltage command. This method was further analyzed in [8] in the z-domain. In [9] and [10], instead of a leadlag compensator, the capacitor voltage was fed back to the voltage command through a high-pass filter. A more complex approach, using both a proportional feedback of the capacitor voltage with its lower frequency component and a lead-lag feedback with its high frequency component, was presented in [11]. In [12]-[14], capacitor current feedback methods were used. Remarkable work on this method was recently presented in [15] and [16], in which a proportional feedback of the capacitor current and a differential feedback of the capacitor voltage were further analyzed in the z-domain, with respect to the ratio of the resonance and control frequency. However, the analysis was based on the ability to damp the closed loop poles of a pre-designed PI controlled system inside unity circle. Since the phase characteristics of a damped LCL filter are quite different than those of an L filter [17], the current controller is more suitable for designing after active damping. Another important work in this area was done in [18] by introducing the concept of a "virtual resistor", in which the differential of the capacitor current was fed back to the reference of the converter-side current to simulate a real damping resistor. Unlike these single state feedback methods, complete state information was used in [19] and [20] for current control. All of these methods require extra sensors to measure additional states in order to achieve the necessary damping, which increases hardware costs and reduces system reliability. In order to overcome these drawbacks, sensorless approaches were proposed in [9] and [21], in which the required states were estimated instead of being measured. However, the control complexity of these methods was high. 


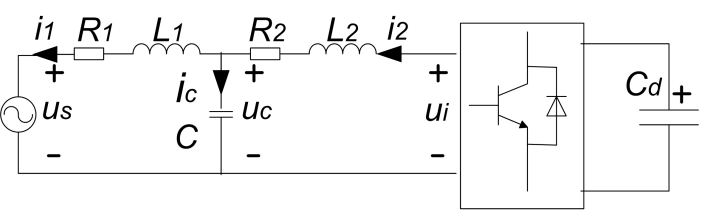

Fig. 1. Voltage source converter with an LCL filter.

In this paper, the active damping methods using single state feedbacks are investigated under the discrete-time statespace model. The damping capabilities of these methods are analyzed based on the pole-location of the transfer function between the current controller output and the grid-side current. This is a benefit for the current controller design. The capacitor current, the capacitor voltage, and the grid-side current are chosen as feedback states. This is because their damping capabilities are only determined by the ratio of the resonance and control frequency, which will be illustrated in section III. Only proportion feedback is considered here because of its simplicity and availability. Theoretical analysis shows that the grid-side current feedback method is more suitable for use in active power filters, because it can damp LCL resonance more effectively than the other two methods when the ratio of the resonance and control frequency is between 0.225 and 0.325 . Furthermore, this method provides a cost-efficient solution, since there is no need for extra sensors for the measurement of additional states. To support the theoretical analysis, the proposed damping method is tested on a 7-kVA active power filter.

\section{SyStem Modeling}

A single-phase voltage source converter is connected to the power grid through an LCL filter, as shown in Fig. 1. The grid voltage $u_{s}$ is measured for the purpose of synchronizing the control with the grid voltage. The grid-side current $i_{2}$ is controlled to track the current reference. $R_{1}$ and $R_{2}$ are the equivalent resistors of the inductors $L_{1}$ and $L_{2} . C$ is the filter capacitor.

The converter-side current $i_{1}$, the grid-side current $i_{2}$ and the capacitor voltage $u_{c}$ are chosen as states. The terminal voltage $u_{i}$ and the grid voltage $u_{s}$ are chosen as inputs. According to Kirchhoff's laws, the continuous state-space model of an LCL filter can be derived as:

$$
\dot{x}^{\prime}(t)=A_{o} x^{\prime}(t)+B_{1} u_{i}(t)+B_{2} u_{s}(t)
$$

where:

$$
\begin{aligned}
& x^{\prime}=\left[\begin{array}{lll}
\mathrm{i}_{1} & i_{2} & u_{c}
\end{array}\right]^{T} \\
& A_{o}=\left[\begin{array}{ccc}
-\mathrm{R}_{1} / \mathrm{L}_{1} & 0 & -1 / \mathrm{L}_{1} \\
0 & -\mathrm{R}_{2} / \mathrm{L}_{2} & -1 / \mathrm{L}_{2} \\
1 / \mathrm{C} & -1 / \mathrm{C} & 0
\end{array}\right] \\
& B_{1}=\left[\begin{array}{lll}
1 / \mathrm{L}_{1} & 0 & 0
\end{array}\right]^{T}, B_{2}=\left[\begin{array}{ccc}
0 & -1 / \mathrm{L}_{2} & 0
\end{array}\right]^{T}
\end{aligned}
$$

In order to accurately model the behavior of a PWM generator, the continuous model is discretized using the zeroorder hold method. The discrete-time state-space model can be derived as:

$$
x^{\prime}(k+1)=G x^{\prime}(k)+H u_{i}(k)+M u_{s}(k)
$$

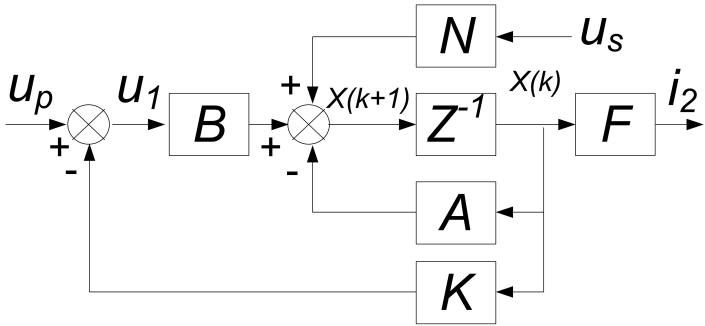

Fig. 2. State feedback for resonance damping.

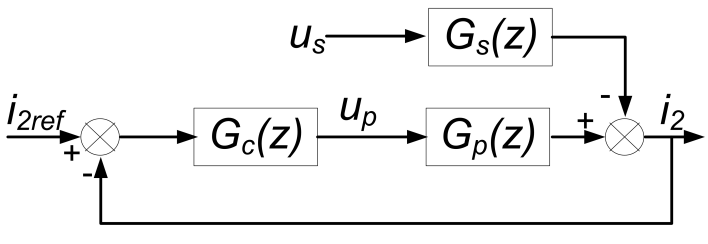

Fig. 3. Equivalent current control diagram.

where, $G=e^{A_{o} T}, \quad H=\int_{0}^{T} e^{A_{o} t} B_{1} d t, \quad M=\int_{0}^{T} e^{A_{o} t} B_{2} d t$, and $T$ denotes for the sampling period.

Due to the sampling and control time of a DSP, the voltage command $u_{1}$ calculated during the present timestep can only affect the terminal voltage $u_{i}$ during the next timestep. This behavior can be modeled as:

$$
u_{i}(k+1)=u_{1}(k) .
$$

By considering $u_{i}$ as an additional state and $u_{1}$ as a new input, this delay can be taken into account in the state-space model by rearranging the state equation [19]. The augmented discrete-time state-space model is then given by:

$$
\begin{aligned}
& x(k+1)=A x(k)+B u_{1}(k)+N u_{s}(k) \\
& y(k)=F x(k)=i_{2}(k)
\end{aligned}
$$

where:

$$
\begin{aligned}
& x=\left[\begin{array}{llll}
i_{1} & i_{2} & u_{c} & u_{i}
\end{array}\right]^{T}, F=\left[\begin{array}{llll}
0 & 1 & 0 & 0
\end{array}\right] \\
& A=\left[\begin{array}{c|c}
G & H \\
\hline 0 & 1
\end{array}\right], B=\left[\begin{array}{c}
0 \\
\hline 1
\end{array}\right], N=\left[\begin{array}{c}
M \\
\hline 0
\end{array}\right]
\end{aligned}
$$

Suppose the output of a current controller is denoted by $u_{p}$ and the state feedback matrix is $K$, as shown in Fig. 2. The transfer function from $u_{p}$ and $u_{s}$ to $i_{2}$ can be derived as:

$$
\begin{aligned}
G_{p}(z) & =F(z I-A+B K)^{-1} B \\
G_{s}(z) & =F(z I-A+B K)^{-1} N .
\end{aligned}
$$

A current control diagram is shown in Fig. 3. $G_{c}(z)$ denotes a current controller. $G_{p}(z)$ denotes an equivalent plant with active damping, or without damping if $K$ equals zero. The damping capabilities of the single state feedback methods are easily studied by analyzing the pole-locations of $G_{p}(z)$, since the state feedbacks do not change their zeros. The characteristic equation of the plant $G_{p}(z)$ is given by:

$$
\left|(z I-A+B K)^{-1}\right|=0 .
$$

For the capacitor current, the capacitor voltage, and the grid-side current feedback methods, their corresponding matrixes $K$ equal to $\left[\begin{array}{llll}k_{1} & -k_{1} & 0 & 0\end{array}\right],\left[\begin{array}{llll}0 & 0 & k_{2} & 0\end{array}\right]$ and $\left[\begin{array}{llll}0 & k_{3} & 0 & 0\end{array}\right]$ respectively. Where $k_{1}, k_{2}$ and $k_{3}$ denote the values of each of the feedback gains. 


\section{DAMPING CAPABILITY ANALYSIS}

To simplify the analysis, the equivalent resistances of the filter inductors are ignored in this section. The characteristic equations for the state feedback methods are shown in Table I. In the equations for the capacitor current feedback and the capacitor voltage feedback, the poles located at unity are unchanged with or without active damping. Therefore, only the locations of the other three poles need to be analyzed. Instead of solving the roots of the characteristic equations, the root-locus of the corresponding transfer functions, as shown in Table I, are studied to analyze the damping capability. Since the values of $\Delta_{1}, \Delta_{2}$, and $\Delta_{3}$ can be tuned (by tuning $k_{1}, k_{2}$ and $k_{3}$ ) by the designer, the only factor determining the damping ability is $\theta$, which is the product of the LCL resonant angle frequency and the sampling period.

For design purposes, the ratio of the resonance and control frequency is more suitable for consideration as the determinant of damping ability. The relationship between the ratio $\gamma$ and $\theta$ is:

$$
\gamma=\theta /(2 \pi) .
$$

Fig. 4 shows the root-locus (only the parts locate inside the unity circle) of the corresponding transfer functions when $\gamma$ changes from 0.05 to 0.4 with intervals of 0.025 . For the capacitor current and the voltage feedback methods, the root-locus is symmetrical with respect to the imaginary axis, because the two transfer functions have the same poles and symmetrical zeros. The max damping factor that can be acquired by each method is shown in Fig. 5. When $\gamma<0.225$, the capacitor voltage feedback is the best way to damp the LCL resonance, when $\gamma>0.325$, the capacitor current feedback is the best choice, and when $0.225<\gamma<0.325$, the grid-side current feedback offers the best damping ability.

Along with the damping factor, the damped frequency and the changes of the rest poles should also be considered. For example, when $\gamma$ is quite small, excess damping using capacitor voltage feedback will cause the damped frequency to be very low, which introduces a large phase lag in low frequencies. As another example, sufficient damping achieved by grid-side current feedback usually makes the rest poles become a pair of conjugate poles, which badly reduces the low frequency gain of $G_{p}(z)$. In such cases, compensation should be included in the current controller.

In addition, the ratio $\gamma$ is not an optional parameter for active damping purposes. The control frequency (or switching frequency) is determined by carefully considering the current control capability and reasonable switching losses, while the resonant frequency is determined for the purpose of harmonic attenuation. The ratio $\gamma$ is determined before the active damping design process. If the current reference is fundamental, such as in the application of active rectifiers and distributed generating systems, the resonant frequency is usually quite low to sufficiently reduce the switching harmonics. This would result in a very small value for $\gamma$, which makes the application of the grid-side current feedback method impossible. The capacitor current or voltage feedback methods are more suitable for damping the LCL resonance in these applications. However, for active power filters, the resonant

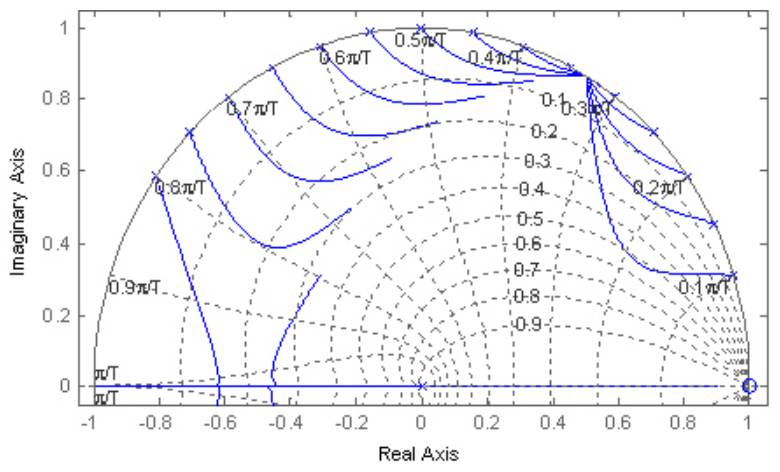

(a)

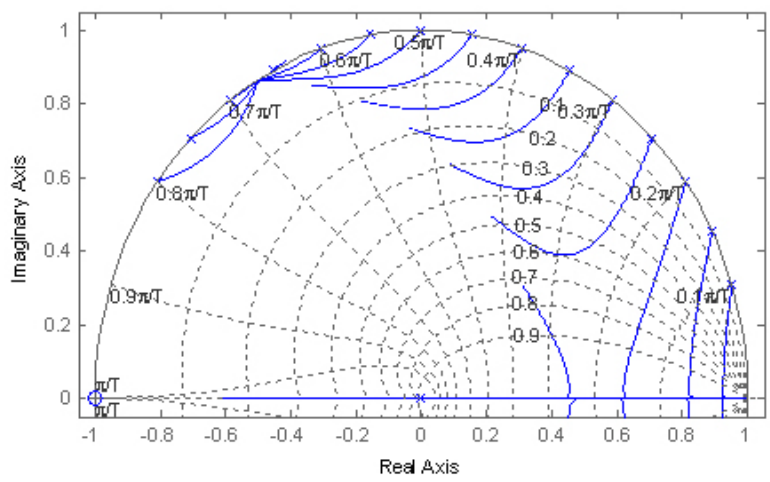

(b)

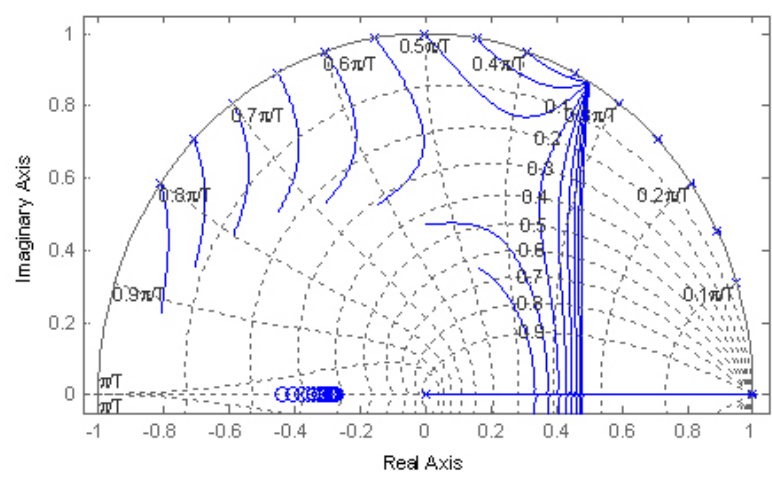

(c)

Fig. 4. The root-locus of the corresponding transfer functions for (a) capacitor current feedback, (b) capacitor voltage feedback, and (c) grid-side current feedback.

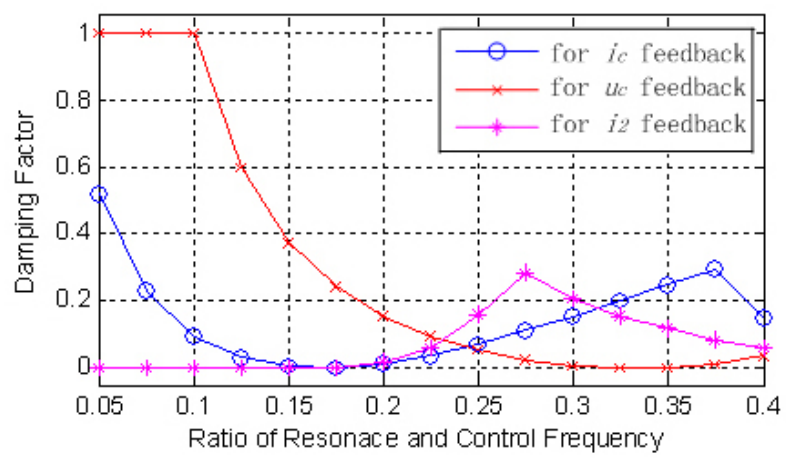

Fig. 5. The max damping factor of state feedbacks vs. $\gamma$. 
TABLE I

The Characteristic Equations AND CORRESPONDING TRANSFER FunCtions

\begin{tabular}{|c|c|c|}
\hline Method & Characteristic equation & Corresponding transfer function \\
\hline$i_{c}$ feedback & $(\mathrm{z}-1)\left(\mathrm{z}^{3}-2 \cos \theta \mathrm{z}^{2}+\left(1+\Delta_{1}\right) \mathrm{z}-\Delta_{1}\right)=0$ & $\frac{\Delta_{1}(z-1)}{z\left(z^{2}-2 \cos \theta z+1\right)}$ \\
\hline$u_{c}$ feedback & $(\mathrm{z}-1)\left(\mathrm{z}^{3}-2 \cos \theta \mathrm{z}^{2}+\left(1+\Delta_{2}\right) \mathrm{z}+\Delta_{2}\right)=0$ & $\frac{\Delta_{2}(z+1)}{z\left(z^{2}-2 \cos \theta z+1\right)}$ \\
\hline$i_{2}$ feedback & $\mathrm{z}^{4}-(1+2 \cos \theta) \mathrm{z}^{3}+\left(1+2 \cos \theta+\Delta_{3}\right) \mathrm{z}^{2}-\left(1+2 \lambda \Delta_{3}\right) \mathrm{z}+\Delta_{3}=0$ & $\frac{\Delta_{3}\left(z^{2}-2 \lambda z+1\right)}{z(z-1)\left(z^{2}-2 \cos \theta z+1\right)}$ \\
\hline \multicolumn{2}{|c|}{ Where $L=\mathrm{L}_{1}+\mathrm{L}_{2}, \omega=\sqrt{L /\left(L_{1} L_{2} C\right)}, \theta=\omega T, \Delta_{1}=k_{1} \sin \theta /\left(\mathrm{L}_{1} \omega\right), \Delta_{2}=k_{2} \mathrm{~L}_{2}(1-\cos \theta) / L, \Delta_{3}=k_{3}(\theta-\sin \theta) /(L \omega), \lambda=(\theta \cos \theta-\sin \theta) /(\theta-\sin \theta)$} \\
\hline
\end{tabular}

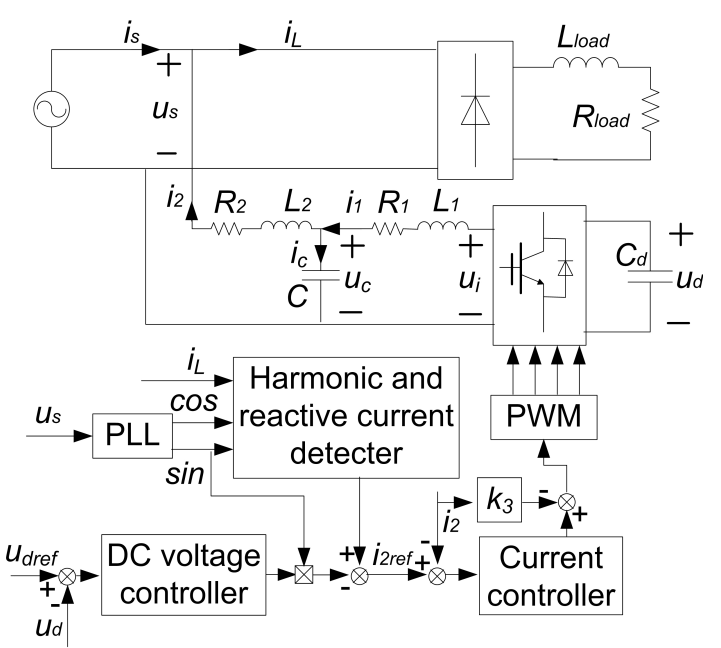

Fig. 6. General diagram of a single-phase shunt APF.

frequency should be much higher to ensure a high current control bandwidth. The value of $\gamma$ is usually in the range of 0.225 to 0.325 . Besides the best damping capability, the grid-side current feedback method dose not require additional measurements, which provides a cost-efficient solution. The application of this method in a single-phase active power filter will be detailed in the following section.

\section{ApPLiCATION IN APF}

The main circuit and the control of a single-phase shunt APF is shown in Fig. 6. The APF has two major tasks. One is to generate a current reference $i_{2 r e f}$, which contains not only harmonics and a reactive current injected by disturbing the load, but also a fundamental active current generated by the dc voltage controller to maintain the dc link voltage. The other one is to control the grid-side current $i_{2}$ to track this current reference, leaving only the fundamental active current to be supplied by the power grid. The main parameters of this APF are shown in Table II. The LCL resonant frequency is $5877 \mathrm{~Hz}$, and the ratio $\gamma$ is 0.2939 .

\section{A. Active Damping}

The grid-side current feedback method is used to damp the LCL resonance in this APF. The resistances ignored in the last section are taken into account for precise analysis. The polezero maps of $G_{p}(z)$ with different values of $k_{3}$, are shown in Fig. 7. As the resonant poles are damped into the unity circle when $k_{3}$ become lager, another pair of conjugate poles is formed and moves towards the unity circle. Both pairs of poles are considered for damping purposes. When $k_{3}$ equals 11 , the maximum damping factor is achieved.

TABLE II

SYSTEM PARAMETERS

\begin{tabular}{|l|l|l|}
\hline Symbol & Quantity & Value \\
\hline$L_{1}$ & Converter-side inductor & $0.66 \mathrm{mH}$ \\
\hline$L_{2}$ & Grid-side inductor & $0.33 \mathrm{mH}$ \\
\hline$R_{1}$ & $\begin{array}{l}\text { Resistance of converter-side in- } \\
\text { ductor }\end{array}$ & $0.066 \Omega$ \\
\hline$R_{2}$ & Resistance of grid-side inductor & $0.033 \Omega$ \\
\hline$C$ & Filter capacitor & $3.3 \mu \mathrm{F}$ \\
\hline$C_{d}$ & dc link capacitor & $2.35 \mathrm{mF}$ \\
\hline$u_{s}$ & Grid voltage & $220 \mathrm{~V}(\mathrm{rms})$ \\
\hline$u_{d r e f}$ & dc link voltage reference & $400 \mathrm{~V}$ \\
\hline$L_{\text {load }}$ & Load inductor & $10 \mathrm{mH}$ \\
\hline$R_{\text {load }}$ & Load resistance & $10 \mathrm{or} 5 \Omega$ \\
\hline$f_{1}$ & Grid frequency & $50 \mathrm{~Hz}$ \\
\hline$f_{s}$ & Switching frequency & $10 \mathrm{kHz}$ \\
\hline$f_{c}$ & Control and sampling frequency & $20 \mathrm{kHz}$ \\
\hline
\end{tabular}

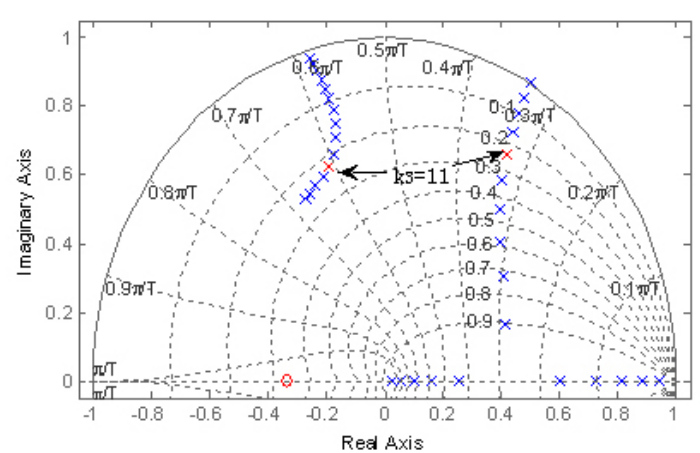

Fig. 7. Pole-zero maps of $G_{p}(z)$ with different $k_{3}$.

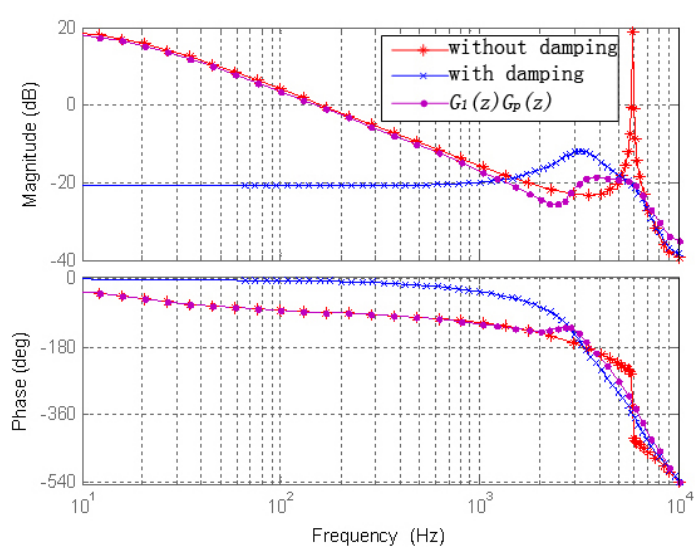

Fig. 8. Bode plots of $G_{p}(z)$ with and without active damping. 
The bode plots of $G_{p}(z)$ both with and without active damping are shown in Fig. 8. Although the LCL resonance is sufficiently damped by the proposed method, the changes in the rest poles badly reduce the low frequency gain of $G_{p}(z)$. Compensation is needed for current control purposes. Since the lower frequency conjugate poles are far from the unity circle, the pole-zero cancellation method can be used to assign the two poles to desired locations. Usually they are the same as $G_{p}(z)$ without damping. However, to compensate the phase lag of $G_{p}(z)$ so as to improve the phase margin of the current control, the compensator transfer function is chosen as:

$$
G_{1}(z)=\frac{z^{2}-1.187 z+0.7}{z(z-0.995)} .
$$

A bode plot of $G_{1}(z) G_{p}(z)$ is also shown in Fig. 8. Its lowfrequency gain is quite close to the plant without damping, and the phase lag compensation is achieved at around $2.5 \mathrm{kHz}$.

\section{B. Current Controller Design}

The current control of shunt APFs is a challenging task, due to the current harmonics that have to be generated. Generalized integrators, with the virtue of infinite gains at concerned harmonic frequencies, can track these harmonic references with zero steady-state error, and are wildly used in shunt APFs. However, to compensate higher order harmonics, the generalized integrator must contain a term of delay compensation [22]. Two types of modified generalized integrators are commonly used for this purpose. One is the sum of the sine and cosine based generalized integrators with desired weights [23], [24], and the other is derived from a vector PI controller in the harmonic frame [22], [25]. The later is adopted in this paper, because it can also relieve of the undesired magnitude peak around the concerned harmonic frequency in a closed loop.

Twenty five generalized integrators are paralleled to compensate for all of the odd harmonics bellow the $50^{\text {th }}$. The transfer function in the $s$-domain can be written as:

$$
G_{2}(s)=\sum_{i=1,3, \cdots, 49} \frac{k_{i} s(L s+R)}{s^{2}+\left(i \omega_{1}\right)^{2}}
$$

where, $\omega_{1}$ is the fundamental angle frequency, $R$ is the sum of $R_{1}$ and $R_{2}$, and $k_{i}$ is the gain for each of the generalized integrators. Values of $k_{i}$ that are too small make the current controller very sensitive to grid frequency variation, and result in a poor dynamic response. Values of $k_{i}$ that are too large deteriorate the system phase margin, and in the worst case they can make the system unstable. The values of $k_{i}$ must be carefully designed. Optimization of these parameters is a difficult job. However, this is beyond the scope of this paper. Here, the same value for each $k_{i}$ is considered. Finally, to ensure a reasonable phase margin, 50 is chosen for each $k_{i}$.

The discrete version of $G_{2}(s), G_{2}(z)$, is derived using the Tustin transformation with a pre-warp at each of the concerned harmonic frequencies. The current controller transfer function and the open loop transfer function can be written as:

$$
G_{c}(z)=G_{2}(z) G_{1}(z)
$$

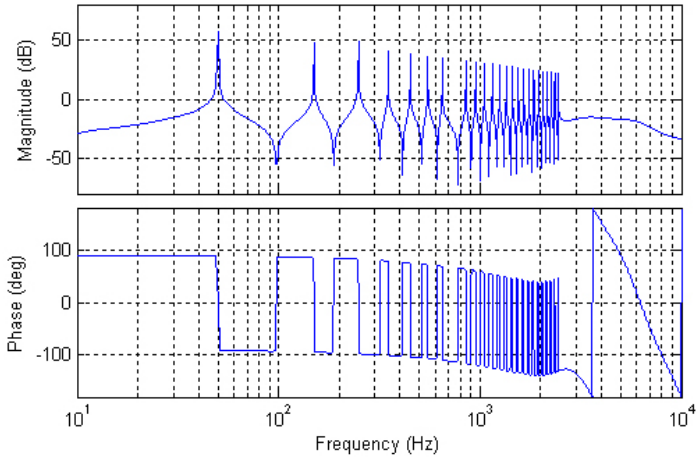

Fig. 9. Bode plot of open loop transfer function.

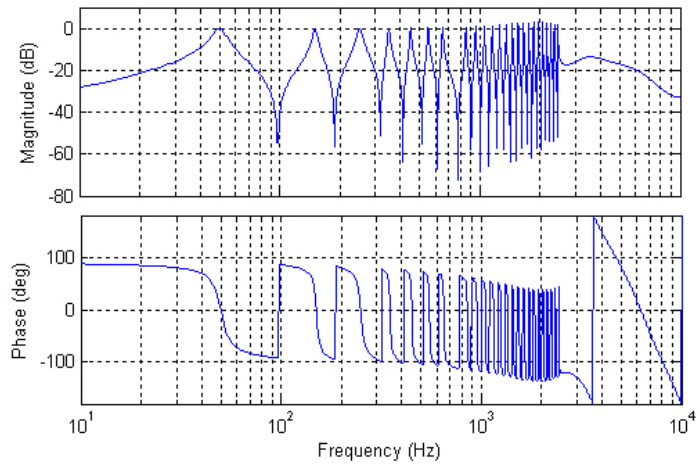

Fig. 10. Bode plot of closed loop transfer function.

$$
G_{\text {open }}(z)=G_{c}(z) G_{p}(z) .
$$

A bode plot of $G_{\text {open }}(z)$ is shown in Fig. 9. The system phase margin is over $40^{\circ}$. A bode plot of closed a loop transfer function is shown in Fig. 10. Unity gain and zerophase are achieved at each concerned harmonic frequency, and the maximum magnitude peak is less than $3 \mathrm{~dB}$.

\section{Influence of the Grid Voltage}

From Fig. 3, the transfer function between the grid voltage and the grid-side current can be derived as:

$$
G_{r}(z)=G_{s}(z) /\left(1+G_{\text {open }}(z)\right)=E(z) G_{s}(z)
$$

where, $E(z)$ denotes the error transfer function of the current control. Bode plots of $G_{s}(z)$ with and without damping are shown in Fig. 11. The LCL resonance is as well damped as $G_{p}(z)$, since they have the same poles. This is very important, because the gain of the error transfer function at high frequencies is almost unity. As a result, an undamped resonance would have a risk of oscillating with the power grid, regardless of whether the control is stable or not.

Furthermore, the low-frequency gain of $G_{s}(z)$ is as sufficiently reduced as $G_{p}(z)$. However, this time it is profitable from the view point of disturbance rejection. The feed forward of the grid voltage is not necessary with the proposed damping method. A bode plot of $G_{r}(z)$ is shown in Fig. 12, which is only different from $G_{s}(z)$ near the concerned harmonic frequencies. This is due to the selectivity of the current controller. 


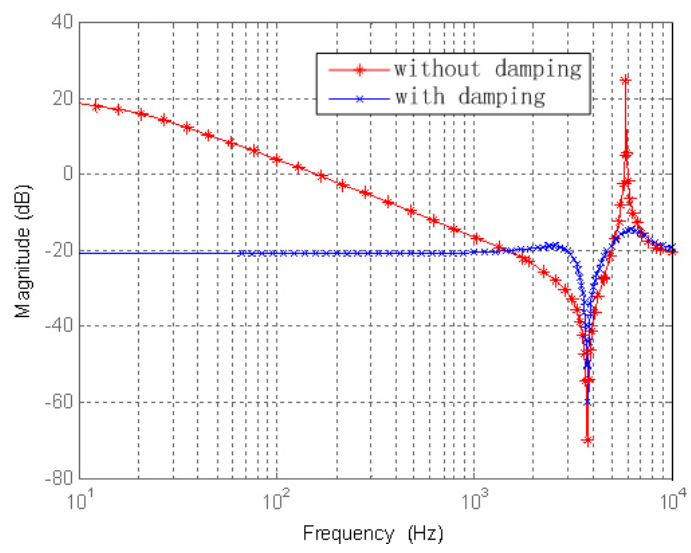

Fig. 11. Bode plots of $G_{s}(z)$ with and without damping.

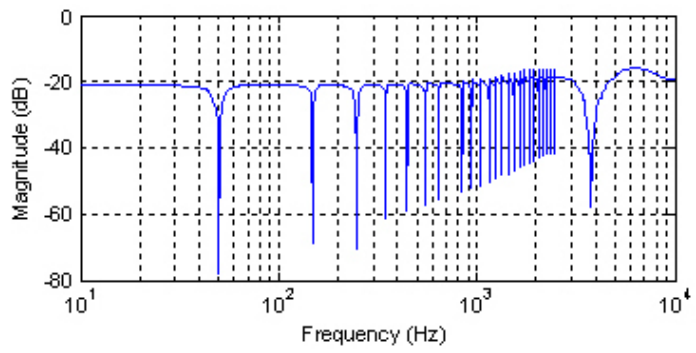

Fig. 12. Bode plot of $G_{r}(z)$.

\section{EXPERIMENTAL RESULTS}

The proposed active damping method is tested on a 7-kVA active power filter as shown in Fig. 6. The system parameters are the same as those presented in section IV. The dc link voltage is controlled by a PI controller with a cut-off frequency of $3 \mathrm{~Hz}$. The grid voltage $u_{s}$ and its $\pi / 2$ lag value (approximated by the value of a fixed timestep delay of $u_{s}$ ) are transferred into the synchronous reference frame. Synchronization of the grid phase is achieved by controlling the q-axis component to be zero. The fundamental active current of the load current $i_{L}$ is extracted by the sliding-window iterative DFT (Discrete Fourier Transform) algorithm. Then the harmonics and the reactive current reference are generated by subtracting the fundamental active current form the load current. All of the control algorithms are implemented with a TMS320F2812 fixed-point DSP. The experimental waveforms are measured using a DL750 scopecorder.

Steady-state waveforms with a load resistance of $5 \Omega$ are shown in Fig. 13. The grid-side current is measured with a bandwidth of $5 \mathrm{kHz}$, because it is measured inside the chest of the APF, and suffers from a high EMI. All other quantities are measured with a full bandwidth. The harmonic spectrum of the grid current after compensation is shown in Fig. 14(a). All of the odd harmonics bellow the $50^{\text {th }}$ are well compensated for due to the generalized integrators. The THD (Total harmonic distortion) of the grid current is less than $4.01 \%$ (0.8\% within 50 order), while the THD of the load current is $38.29 \%$. The appearance of a small protuberance at around $6 \mathrm{kHz}$ in the grid current spectrum is not caused by the pool damping. The load current spectrum has the same one, as in Fig. 14(b).

The damping and control performance is also tested under transient conditions. Fig. 15 shows the APF behavior when it

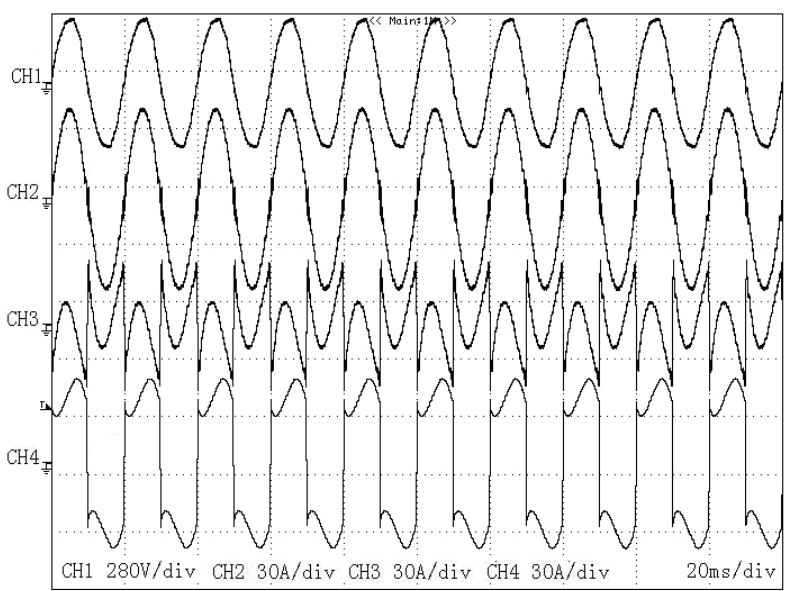

Fig. 13. Steady-state waveforms with load resistance of $5 \mathrm{~W}$. (Form top to bottom) Grid voltage $\left(u_{s}\right)$, grid current $\left(i_{s}\right)$, grid-side current $\left(i_{2}\right)$, and load current $\left(i_{L}\right)$.

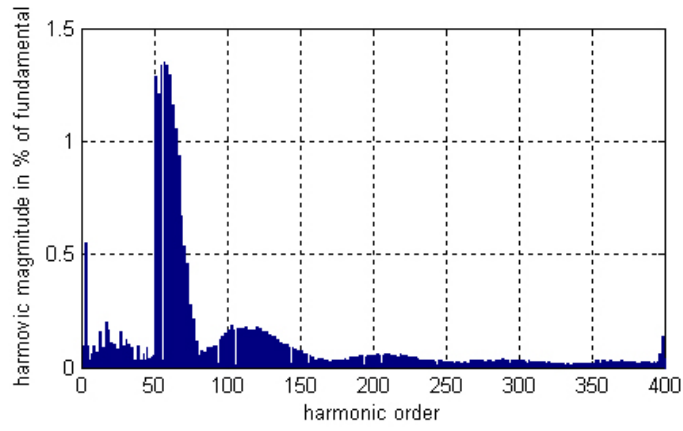

(a)

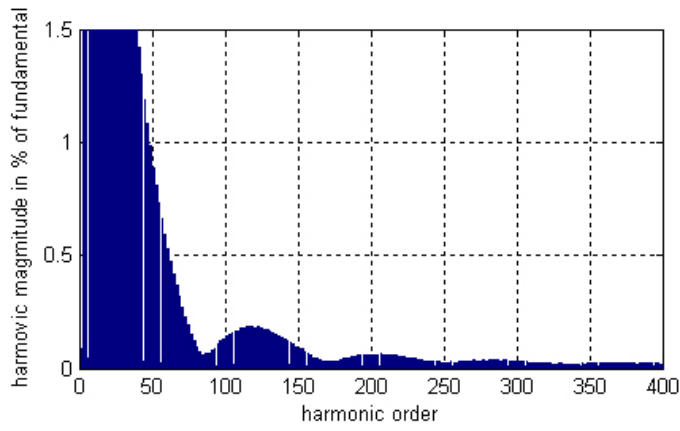

(b)

Fig. 14. Harmonic spectrum in steady-state of (a) grid current and (b) load current.

starts to compensate for the load disturbing current. The load resistance is $10 \Omega$ in Fig. 15(a), and $5 \Omega$ in Fig. 15(b). The transient performance of the APF, when the load resistance changes from $10 \Omega$ to $5 \Omega$, is shown in Fig. 16. In all of these conditions, no oscillation occurs in the transient process, and the transient time is about $100 \mathrm{~ms}$.

\section{CONCLUSION}

Active damping methods using capacitor current, capacitor voltage, and grid-side current feedbacks, are analyzed in this paper. Their damping abilities are determined by the ratio of the resonance and control frequency. When the ratio is smaller than 0.225 , the capacitor voltage feedback method 


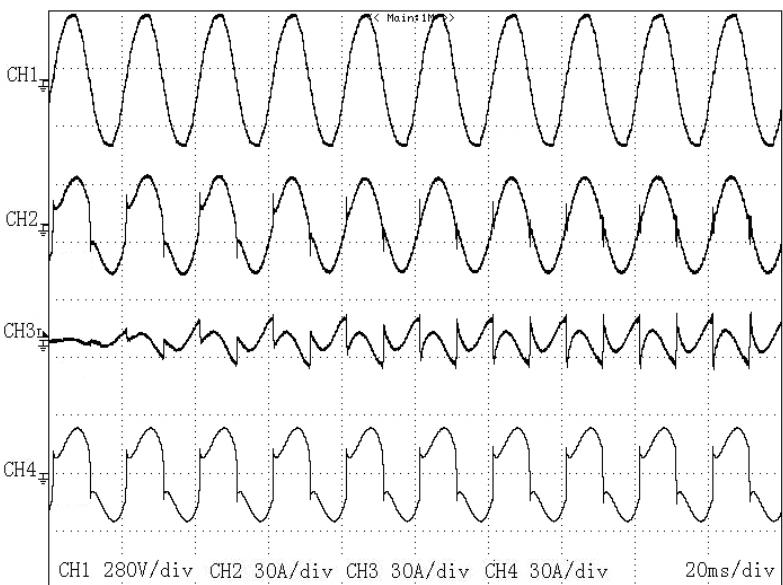

(a)

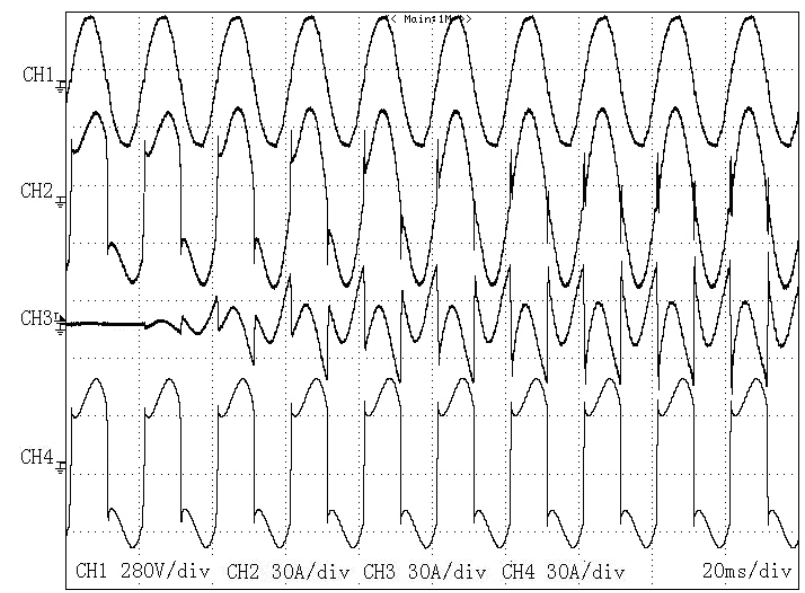

(b)

Fig. 15. Transient waveforms when APF start to compensate harmonics with load resistance of (a) $10 \Omega$ and (b) $5 \Omega$. (Form top to bottom) Grid voltage $\left(u_{s}\right)$, grid current $\left(i_{s}\right)$, grid-side current $\left(i_{2}\right)$, and load current $\left(i_{L}\right)$.

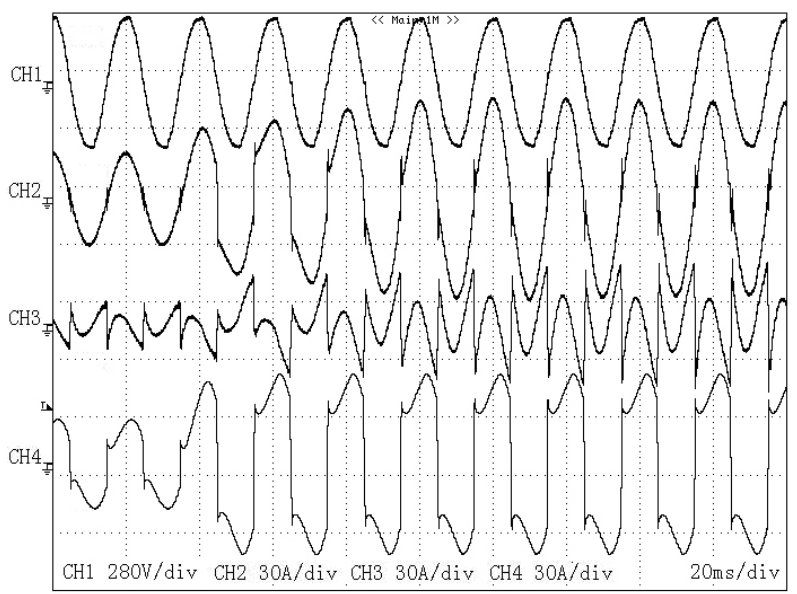

Fig. 16. Transient waveforms when load resistance change form $10 \Omega$ to $5 \Omega$. (Form top to bottom) Grid voltage $\left(u_{s}\right)$, grid current $\left(i_{s}\right)$, grid-side current $\left(i_{2}\right)$, and load current $\left(i_{L}\right)$. is the best way to damp the LCL resonance, when the ratio is larger than 0.325 , the capacitor current feedback method is the best choice, and when the ratio is in the range of 0.225 to 0.325 , which is quite similar to that of active power filters, the grid-side current feedback method offers the best damping capability. Another advantage of this method is that there is no need for additional measurements, which provides a cost-efficient solution. Furthermore, feed forward of the grid voltage is not necessary, because the low-frequency gain of the transfer function from the grid voltage to the gridside current is sufficiently reduced with this damping method. Experimental results on a 7-kVA active power filter verify the theoretical analysis.

\section{ACKNOWLEDGMENT}

This work was supported by the National Natural Science Foundation of China under Grant No. 50777025

\section{REFERENCES}

[1] M. Liserre, F. Blaabjerg, and S. Hansen, "Design and control of an LCL filter-based three-phase active rectifier," IEEE Trans. Ind. Appl., Vol. 41, No. 5, pp. 1284-1285, Sep./Oct. 2005.

[2] I. J. Gabe, V. F. Montagner, and H. Pinheiro, "Design and implementation of a robust current controller for VSI connected to the grid through an LCL filter,' IEEE Trans. Power Electron., Vol. 24, No. 6, pp. 14441452, Jun. 2009.

[3] O. Vodyakho and C. C. Mi, "Three-level inverter-based shunt active power filter in three-phase three-wire and four-wire systems," IEEE Trans. Power Electron., Vol. 24, No. 5, pp. 1350-1363, May 2009.

[4] B. Bolsens, K. D. Brabandere, J. V. D. Keybus, J. Driesen, and R. Belmans, "Model-based generation of low distortion currents in gridcoupled PWM-inverters using an LCL output filter," IEEE Trans. Power Electron., Vol. 21, No. 4, pp. 1032-1040, Jul. 2006.

[5] D. E. Kim and D. C. Lee, "Feedback linearization control of gridinteractive PWM converters with LCL filters," Journal of Power Electronics, Vol. 9, No. 2, pp. 288-299, Mar. 2009.

[6] M. Routimo and H. Tuusa, "LCL type supply filter for active power filter-Comparison of an active and a passive method for resonance damping," in Proc. IEEE PESC, pp. 2939-2945, 2007.

[7] V. Blasko and V. Kaura, "A novel control to actively damp resonance in input LC filter of a three-phase voltage source converter," IEEE Trans. Ind. Appl., Vol. 33, No. 2, pp. 542-550, Mar./Apr. 1997.

[8] M. Liserre, A. Dell' Aquila, and F. Blaabjerg, "Stability improvement of an LCL-filter based three-phase active rectifier," in Proc. Power Electron. Spec. Conf., pp. 1195-1201, 2002.

[9] B. Bolsens, K. De Brabandere, J. Van den Keybus, J. Driesen, and R. Belmans, "Three-phase observer-based low distortion grid current controller using an LCL output filter," in Proc. IEEE Power Electron. Spec. Conf., pp. 1705-1711, 2005.

[10] S. Nuilers and B. Neammanee, "Control performance of active damp LCL filter of three phase PWM boost rectifier," in Proc. Electron. Info. Conf., pp. 259-263, 2010.

[11] S. Y. Yang, X. Zhang, C. W. Zhang, and Z. Xie, "Study on active damping methods for voltage source converter with LCL input filter," in Proc. Power Electron. Motion Contr. Conf., pp. 975-979, 2009.

[12] E. Twining and D. G. Holmes, "Grid current regulation of a three-phase voltage source inverter with an LCL input filter," IEEE Trans. Power Electron., Vol. 18, No. 3, pp. 888-895. May 2003.

[13] L. Mihalache, "A high performance DSP controller for three-phase PWM rectifiers with ultra low input current THD under unbalanced and distorted input voltage," in Conf. Rec. IEEE IAS Annu. Meeting, pp. 138-144, 2005.

[14] G. Zeng, R. Tonny, L. Ma, and T. Remus, "Design and control of LCLfilter with active damping for Active Power Filter," in Proc. StateInd. Electron. Conf., pp. 2557-2562, 2010.

[15] J. Dannehl, F. Fuchs, S. Hansen, and P. Thegersen, "Investigation of active damping approaches for pi-based current control of gridconnected pulse width modulation converters with LCL filters," IEEE Trans. Ind. Appl., Vol. 46, No. 4, pp. 1509-1517, Jul./Aug. 2010. 
[16] J. Dannehl, C. Wessels, and F. W. Fuchs, "Voltage-oriented PI current control of grid-connected PWM rectifiers with LCL-filter," IEEE Trans. on Ind. Electron., Vol. 56, No.2, pp. 380-388, Feb. 2009.

[17] Y. Tang, P. C. Loh, P. Wang, F. H. Choo, and F. Gao, "Exploring inherent damping characteristic of LCL-filters for three-phase grid-connected voltage source inverters," in Proc. Energ. Conver. Congress Conf., pp. 312-319, 2010.

[18] F. A. Magueed and J. Svensson, "Control of VSC connected to the grid through LCL-filter to achieve balanced currents," in Conf. Rec. IEEE IAS Anпи. Meeting, pp. 572-578, 2005.

[19] E. Wu and P. W. Lehn, "Digital current control of a voltage source converter with active damping of LCL resonance," IEEE Trans. Power Electron., Vol. 21, No. 5, pp. 1364-1373, Sep. 2006.

[20] B. Bolsens, K. De Brabandere, J. Van den Keybus, J. Driesen, and R. Belmans, "Three-phase observer-based low distortion grid current controller using an LCL output filter," in Proc. IEEE Power Electron. Spec. Conf., pp. 1705-1711, 2005.

[21] M. Malinowski and S. Bernet, "A simple voltage sensorless active damping scheme for three-phase PWM converters with an LCL filter," IEEE Trans. Ind. Electron., Vol. 55, No. 4, pp. 1876-1880, Apr. 2008.

[22] C. Lascu, L. Asiminoaei, I. Boldea, and F. Blaabjerg, "Frequency response analysis of current controllers for selective harmonic compensation in active power filters," IEEE Trans. Ind. Electron., Vol. 56, No. 2, pp. 337-347, Feb. 2009.

[23] R. I. Bojoi, G. Griva, V. Bostan, M. Guerriero, F. Farina, and F. Profumo, "Current control strategy for power conditioners using sinusoidal signal integrators in synchronous reference frame," IEEE Trans. Power Electron., Vol. 20, No. 6, pp. 1402-1412, Nov. 2005.

[24] D. G. Holmes, T. A. Lipo, B. P. McGrath, and W. Y. Kong, "Optimized design of stationary frame three phase AC current regulators," IEEE Trans. Power Electron., Vol. 24, No. 11, pp. 2417-2426, Nov. 2009.

[25] C. Lascu, L. Asiminoaei, I. Boldea, and F. Blaabjerg, "High performance current controller for selective harmonic compensation in active power filters," IEEE Trans. Power Electron., Vol. 22, No. 5, pp. 1826-1835, Sep. 2007.

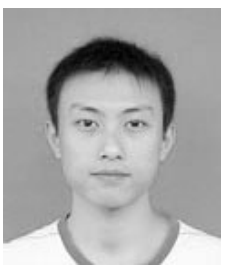

Shiying Tang was born in Chongqing, China, in 1983. $\mathrm{He}$ received his B.S. and M.S. in Electrical and Electronic Engineering from the Huazhong University of Science and Technology, Wuhan, China, in 2005 and 2007, respectively. He is currently working towards his $\mathrm{Ph} . \mathrm{D}$. in Electrical and Electronic Engineering at the Huazhong University of Science and Technology. His research interests include the control and application of power electronic conversions.

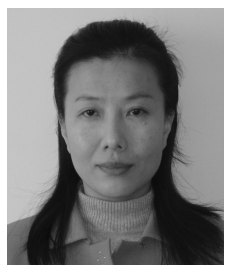

Li Peng was born in Wuhan, China, in 1967. She received her B.E., M.E. and Ph.D. in Electrical and Electronic Engineering from the Huazhong University of Science and Technology, Wuhan, China, in 1989, 1992, and 2004, respectively. Since 1992, she has been with the Department of Electrical and Electronic Engineering, Huazhong University of Science and Technology, where she is currently a Professor. Her research interests include the control and application of power

electronic conversions.

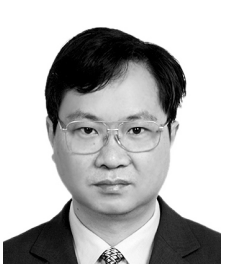

Yong Kang was born in Hubei, China, in 1965. He received his B.E., M.E. and Ph.D. in Electrical and Electronic Engineering from the Huazhong University of Science and Technology, Wuhan, China, in 1988 , 1991, and 1994, respectively. Since 1994, he has been with the Department of Electrical and Electronic Engineering, Huazhong University of Science and Technology, where he is currently a Professor. His research interests include power electronic converters, AC drives, renewable energy generation, modularizing power supply techniques, power electronics applications in electric power systems, EMCs, and their digital control techniques. He is the author of over 100 technical papers. 